\title{
Oxytocin at Physiological Concentrations Evokes Adrenocorticotropin (ACTH) Release from Corticotrophs by Increasing Intracellular Free Calcium Mobilized Mainly from Intracellular Stores. Oxytocin Displays Synergistic or Additive Effects on ACTH-Releasing Factor or Arginine Vasopressin-Induced ACTH Secretion, Respectively*
}

\author{
HEIKE LINK, GOVINDAN DAYANITHI, KARL JOSEF FÖHR, AND \\ MANFRED GRATZL
}

Abteilung Anatomie und Zellbiologie der Universität Ulm (H.L., M.G.), D-7900 Ulm, Deutschland; Centre de Neurochimie du CNRS (G.D.), F-67084 Strasbourg, France; and Naturwissenschaftliches und Medizinisches Institut an der Universität Tübingen in Reutlingen (K.J.F.), D-7410 Reutlingen, Deutschland

\begin{abstract}
The potency of oxytocin (OT) in evoking ACTH secretion by isolated, superfused rat adenohypophyseal corticotrophs and its enhancement by $\mathrm{CRF}$ and arginine vasopressin (AVP) were analyzed. Each secretagogue effectively released ACTH from adenohypophyseal cells when added separately in pulsatile fashion in physiological concentrations based on hypophyseal portal blood (OT, $10 \mathrm{nM}$; AVP, $0.5 \mathrm{nM}$; CRF, $0.1 \mathrm{nM}$ ). OT released ACTH at concentrations as low as $1 \mathrm{nM}$. Moreover, a dose-response relationship up to $10 \mu \mathrm{M}$ was revealed. Combinations of a constant amount of CRF $(0.1 \mathrm{nM})$ with increasing concentrations of OT exerted a synergistic effect on ACTH release. In contrast, OT given in various concentrations in combination with AVP $(0.5 \mathrm{nM})$ produced an additive effect on ACTH release.
\end{abstract}

To study the mechanism of action of OT on ACTH secretion, cytosolic free calcium levels in single pituitary cells exposed to OT or AVP were measured using the calcium-sensitive fluorescent indicator Fura-2. Corticotrophs among mixed adenohypophyseal cell types in the primary cultures were identified by immunocytochemistry. More than 500 cells were individually stimulated with OT or AVP. Basal cytosolic free calcium levels ranged between $80-130 \mathrm{nM}$ free calcium. The addition of $100 \mathrm{nM}$ OT or $1 \mu \mathrm{M}$ AVP increased the cytosolic free calcium concentration within $3 \mathrm{sec}$ to values ranging from $500-800 \mathrm{nM}$. An increase in intracellular calcium ranging from $200-500 \mathrm{nM}$ due to OT could still be observed after extracellular calcium depletion.

Taken together, our data demonstrate that physiological concentrations of OT stimulate ACTH secretion, independent of the other ACTH secretagogues, by mobilizing calcium mainly from intracellular stores. (Endocrinology 130: 2183-2191, 1992)
$\mathrm{S}$ ECRETION of ACTH by the adenohypophysis is controlled by hypothalamic releasing hormones such as CRF and arginine vasopressin (AVP) (1-3). Yet, accumulating evidence supports the notion that oxytocin $(\mathrm{OT})$, in addition to its well-established role in parturition and lactation, also participates in regulation of stress-induced ACTH secretion through the hypothalamo-hypophyseal axis $(4,5)$. Several findings indicate

Received September 30, 1991.

Address correspondence and requests for reprints to: Dr. G. Dayanithi, Laboratoire de Neurobiologie Endocrinologique, Université de Montpellier-2 URA 1197-CNRS, Place Eugène Bataillon, F-34095 Montpellier Cedex-5; France.

* Supported by grants from the Deutsche Forschungsgemeinschaft (Gr 681) and Association National de la Recherche Technique, PROCOPE 92126. G. Dayanithi is a fellow of the Alexander von HumboldtStiftung, Germany. the existence of separate receptors for OT and vasopressin in the rat adenohypophysis $(6,7)$, reinforcing the notion that OT may function as a hypophysiotropic hormone. In addition, CRF-, AVP- and OT-containing neurons in the hypothalamic paraventricular and supraoptic nuclei project to the median eminence and release these peptides into hypophyseal portal blood (810). Here, the concentration of these peptides are several times greater compared to peripheral blood (11-15). Thus, OT as a part of this hypophysiotropic cocktail in the adenohypophyseal circulation could contribute to physiological regulation of ACTH secretion by the hypothalamus.

To date, studies examining the effects of OT on ACTH release have not revealed evidence that $O T$ alone, in physiological concentrations (10 nM), induces ACTH 
release $(16,17)$. Available data demonstrate that AVP, in vitro $(18,19)$ and in vivo $(20)$, and OT (16) augment the ACTH release in response to CRF; but no effects of OT on the ACTH release in response to AVP were reported $(21,22)$. Recently, a kinetic analysis revealed synergistic effects of AVP and CRF on ACTH release (23). Therefore, the present study was designed to examine the ACTH release responses from isolated, superfused rat adenohypophyseal cells to pulsatile additions of physiological concentrations of $\mathrm{OT}$ in the presence or absence of CRF or AVP to determine whether these peptides enhance ACTH release.

Furthermore, mechanism(s) which mediate secretagogue actions in rat adenohypophyseal corticotrophs leading to the release of ACTH utilize different intracellular signal transduction pathways depending on the secretagogue involved. Increases in intracellular calcium have been associated with the action of AVP (24-26). But, the precise mechanism of OT action on ACTH secretion has not been elucidated. Therefore, the role of calcium ions in the mechanism of OT action was studied by measuring cytosolic free calcium levels after a stimulus of OT or AVP in single, immunocytochemically identified corticotrophs. We provide direct evidence, implying that OT acts by mobilizing intracellular stored calcium.

\section{Materials and Methods}

\section{Animals}

Randomly cycling female rats (Wistar, 250-350 g body weight), obtained from Charles River Wiga $\mathrm{GmbH}$, Sulzfeld, Germany, were maintained at 21-23 C with $12 \mathrm{~h}$ light, $12 \mathrm{~h}$ dark cycle (light on between $0700 \mathrm{~h}$ and $1900 \mathrm{~h}$, local time) with free access to pelleted food and tap water. For each experiment ten animals, usually taken from separate cages in order to avoid stress-induced activation of the hypothalamohypophyseal system, were killed by decapitation (between 0800 $\mathrm{h}$ and $0900 \mathrm{~h}$ ). The adenohypophyses were quickly removed and further processed as described below.

\section{Chemicals}

Chemicals and reagents were obtained from the following sources: OT, Boehringer Mannheim (Mannheim, Germany); AVP, Bachem (Budendorf, Switzerland); trypsin (code TRL), Worthington Biochemical Corp (Freehold, NJ); medium [Dulbecco's minimal essential medium (MEM)] for cell culture, Biochrom KG (Berlin, Germany); Dulbecco's MEM for perfusion experiments, Flow Laboratories (Irvine, Scotland); fetal calf serum (FCS), Gibco (Berlin, Germany); BSA (tissue culture grade), Miles Laboratories (Elkhart, IN); Fura-2 and Fura-2/ AM (pentaacetoxymethylester), Calbiochem (La Jolla, CA); EGTA, Fluka (Neu-Ulm, Germany). All other chemicals, including rat CRF-41, human $\mathrm{ACTH}_{1-39}$, DNAse I, antibioticantimycotic solution (specified below), HEPES, trypsin inhibitor (from soybean), and aprotinin were purchased from Sigma (Deisenhofen, Germany).

\section{Isolation of adenohypophyseal cells}

Anterior pituitary cells were isolated as described previously (27-29). Briefly, the excised adenohypophyses were placed in medium A (Dulbecco's MEM, buffered with $22 \mathrm{mM}$ HEPES at pH 7.4, containing $0.25 \% \mathrm{BSA}$ and antibiotic-antimycotic substances: Penicillin G, $100 \mathrm{U} / \mathrm{ml}$; Streptomycin, $100 \mu \mathrm{g} / \mathrm{ml}$; Amphotericin B, $0.25 \mu \mathrm{g} / \mathrm{ml}$ ) and minced to approximately 0.5 $\mathrm{mm}$ diameter segments. The tissue fragments were then enzymatically dissociated by incubation in the above medium containing DNAse I $(5 \mu \mathrm{g} / \mathrm{ml})$ and trypsin $(0.25 \%)$ for $20 \mathrm{~min}$ at $37 \mathrm{C}$ in a shaking water bath. The cells were further dispersed by mechanical trituration for $10 \mathrm{~min}$ in the trypsin solution and the cell suspensions centrifuged for $8 \mathrm{~min}$ at $200 \times \mathrm{g}$. The supernatant was discarded, and the pellet was resuspended in $10 \mathrm{ml}$ of the above medium containing trypsin-inhibitor $\mathbf{0 . 5}$ $\mathrm{mg} / \mathrm{ml}$ ) and aprotinin ( 0.25 trypsin inhibitor units/ml) and centrifuged as above, and the final pellet was resuspended in medium A.

\section{Superfusion and stimulation of cells}

Aliquots of cell suspensions containing approximately $3.5 \times$ $10^{6}$ cells were mixed with $1 \mathrm{ml}$ preswollen Sephadex G-10 (Pharmacia; Uppsala, Sweden). Equal amounts of cell suspensions were then transferred onto perifusion columns (chamber volume was adjusted to $0.4 \mathrm{ml}$ ) made from disposable $2 \mathrm{ml}$ syringes, which were kept in a thermostated incubator at $37 \mathrm{C}$. Perifusion with medium A was carried out according to previously described methods $(29,30)$ using a multichannel peristaltic pump (Ismatec IPN-8; Zürich, Switzerland) at a flow rate of $0.25 \mathrm{ml} / \mathrm{min}$. After an equilibration period of $2 \mathrm{~h}$, which is required for basal hormone output to decrease to a low and constant level $(29,30)$, two priming secretagogue pulses, containing $0.05 \mathrm{nM}$ CRF plus $10 \mathrm{nM}$ OT, were applied to the columns for $5 \mathrm{~min}$ every $30 \mathrm{~min}$ to synchronize ACTH release from the cells (31). Then secretagogues were applied every 30 min in a balanced random blocks design to four parallel columns. During the experimental period, 2 min fractions of the column effluents were collected using a microfraction collector (model 203; Gilson Medical Electronics, Villiers le Bel, France); samples were immediately frozen and stored at $-20 \mathrm{C}$ for subsequent RIA. Fifty microliter aliquots of the effluent were assayed for immunoreactive ACTH by RIA with a double antibody precipitation technique (16) using antiserum no. 6 (courtesy of G. B. Makara and K. Kovacs, Budapest, Hungary). Purified human $\mathrm{ACTH}_{1-39}$ was used as the assay standard.

\section{Data analysis}

During a 5 min exposure to secretagogues, the concentrations of ACTH in the column effluent increased for $10 \mathrm{~min}$, that is in five consecutive $2 \mathrm{~min}$ fractions. Net ACTH release for each stimulus was obtained by subtracting the basal value measured immediately before the application of a stimulus. Data are expressed as the mean \pm SEM. Statistical evaluation was performed by two-way nonparametric analysis of variance, followed by Student's two-tailed unpaired $t$ test. 


\section{Primary cultures of pituitary cells}

Adenohypophyses were removed under sterile conditions, and the cells were isolated as described above using medium B (Dulbecco's MEM for culture buffered with $44 \mathrm{mM}$ sodium hydrogen carbonate at $\mathrm{pH} 7.2$, containing $37 \mathrm{mM}$ glucose and antibiotic-antimycotic substances: Penicillin, $500 \mathrm{U} / \mathrm{ml}$; Streptomycin, $500 \mu \mathrm{g} / \mathrm{ml}$ ) containing $10 \% \mathrm{BSA}$. Aliquots of cell suspensions were plated in poly-L-lysine-coated plastic petridishes with medium $B$ containing $20 \mathrm{mM}$ cytosine- $\beta$-D-arabinofuranoside and $5 \%$ FCS and incubated in a humidified atmosphere (5\% $\mathrm{CO}_{2} / 95 \%$ air) at $37 \mathrm{C}$ for 3 days. The medium was changed after $24 \mathrm{~h}$ and subsequently every 2 days.

\section{Measurement of intracellular free calcium of single cells}

Cultured pituitary cells were washed with FCS-free medium to remove serum before loading the cells with Fura-2/AM, which was first dissolved in pure dimethyl sulfoxide and then diluted with FCS-free medium to $1.5 \mu \mathrm{M}$ Fura-2/AM and $0.1 \%$ dimethyl sulfoxide. Dye loading was carried out for 15-30 min at $37 \mathrm{C}$. Subsequently the cells were washed with measuring buffer [in millimolar concentration: $140 \mathrm{NaCl} ; 4.7 \mathrm{KCl} ; 1.2$ $\mathrm{KH}_{2} \mathrm{PO}_{4} ; 1.2 \mathrm{MgSO}_{4} ; 1 \mathrm{CaCl}_{2} ; 0.5$ ascorbic acid; 11 glucose; 15 piperazine- $N, N^{\prime}$-bis(2-ethanesulfonic acid), $\mathrm{pH}$ 7.2] and used for $\mathrm{Ca}^{2+}$ measurement studies up to $4 \mathrm{~h}$ after dye loading. Fluorescence measurements of intracellular calcium were performed with the Zeiss Microscope Photometer System (FFP). The system is based on an inverted microscope (Axiovert 35), equipped for epifluorescence. A Xenon lamp (Wotan, XBO 75 $W / 2$ ) with quartz collector is used for excitation. Interference filters of $340 / 10 \mathrm{~nm}$ and $380 / 10 \mathrm{~nm}$ are alternatively mounted in the filter wheel. In this configuration, the two excitation wavelengths can be changed with a frequency of $200 \mathrm{~Hz}$, resulting in a maximum time resolution of $5 \mathrm{msec}$. The light is deflected by a dichroic mirror (Zeiss FT 425) through the microscope objective (Zeiss LD Achroplan 40x Ph2) to the cells to be analyzed. Fluorescence light from an area adjusted to the cell size, approximately $10 \mu \mathrm{m}$ in diameter, is collected.

With fluorescence values corrected for background and dark current, ratio calculations of the $340 \mathrm{~nm}$ recordings divided by the $380 \mathrm{~nm}$ recordings were carried out according to Grynkiewicz et al. (32).

Test substances were added with a motor-driven syringe (Hamilton microlab P system, Bonaduz, Switzerland; speed setting 9). All test substances were diluted with the measuring buffer and added in a total volume of $25 \mu \mathrm{l}$. This method permitted rapid and highly reproducible changes of the medium surrounding a selected cell. Five to ten cells from one culture dish were randomly selected and measured while stimuli were applied. The responding cells were video-printed. The cells were then washed twice with measuring buffer and, after a 1015 min intermission, the same or a different cell was subjected to the next secretagogue treatment.

\section{Immunocytochemistry of analyzed cells}

After calcium measurements corticotrophs were identified among the mixed cell population in the cultures by immunocytochemistry. Cultures were fixed in cold paraformaldehyde (4\% in $10 \mathrm{mM}$ PBS, pH 7.2) for $30 \mathrm{~min}$ before anti-ACTH antiserum (courtesy of G. B. Makara and K. Kovacs; Budapest, Hungary) was applied in a dilution of 1:2000 in phosphate (10 $\mathrm{mM}$ )-buffered saline containing $0.5 \%$ BSA. Incubation was carried out overnight at $4 \mathrm{C}$. Antigen-antibody complexes were visualized by the double antibody avidin-biotin-peroxidase complex (ABC) technique (Avidin Biotin Complex Vectastainkit, Vector Laboratories; Burlingham, CA) according to a previously published procedure (33). Staining was developed with 3,3'-diaminobenzidine-tetrahydrochloride (Aldrich, Milwaukee, WI) in the presence of $0.01 \% \mathrm{H}_{2} \mathrm{O}_{2}$, dissolved in Tris- $\mathrm{HCl}$ buffer ( $50 \mathrm{~mm}, \mathrm{pH} 7.6$ ). Controls consisted of 1) omitting the first antiserum and incubations with respective buffers (antibody specificity) and 2) incubation with normal rabbit serum (1:2000) instead of the specific antiserum (method specificity). The coordinates of the cells stained on the plate allowed identification of the cells previously analyzed for intracellular calcium concentrations.

\section{Results}

\section{$A C T H$ response to OT by perifused adenohypophyseal cells}

Dispersed rat adenohypophyseal cells were challenged with secretagogue treatments in a column perifusion system. Fig. 1 shows the ACTH responses to five subsequent pulses of $10 \mathrm{nM}$ OT. The cells were repeatedly exposed to $\mathrm{OT}$ stimulation every $30 \mathrm{~min}$ for a $5 \mathrm{~min}$

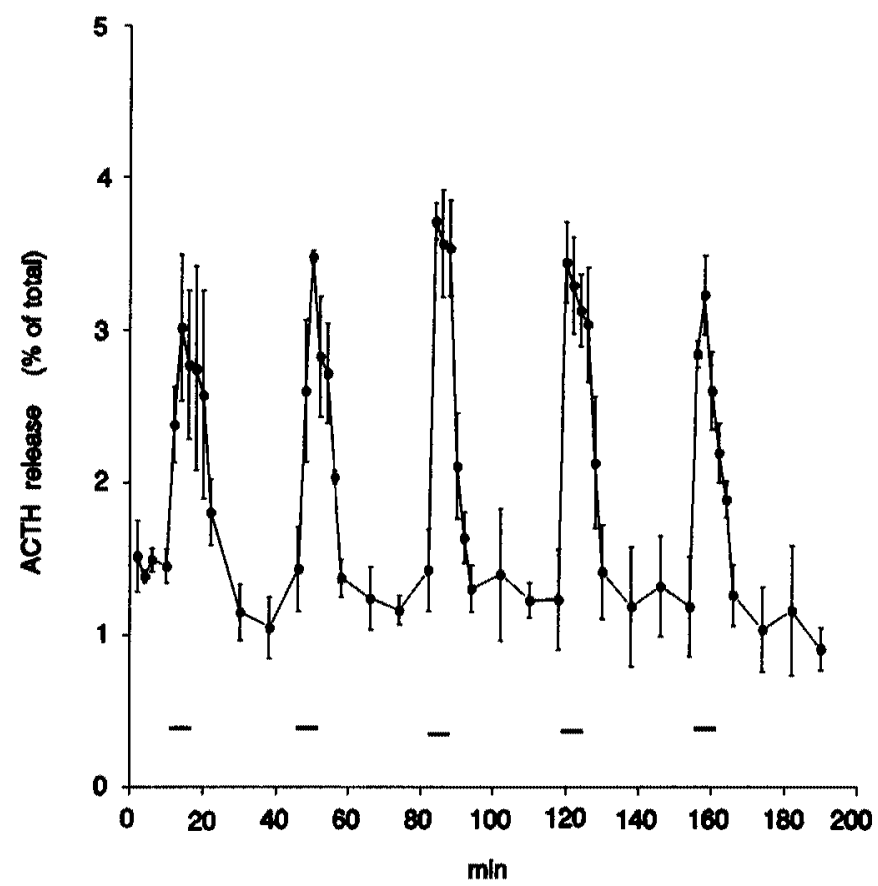

FIG. 1. ACTH release by perifused adenohypophyseal cells in response to consecutive stimuli of $10 \mathrm{nM}$ OT. Data are expressed as percent of total ACTH released from the respective columns during $190 \mathrm{~min}$ of the experimental period and detected in the 2 min fractions. Horizontal bars indicate application of OT for $5 \mathrm{~min}$; points represent means of three experiments; vertical bars show the SEM. The basal rate of ACTH secretion in this experiment was $2 \pm 0.4 \mathrm{fmol} / 2 \mathrm{~min}$ fraction of one column. 
period as indicated by the horizontal bars. The rate of basal ACTH release was $1-1.5 \%$ of the total release, which corresponded to $2 \pm 0.4 \mathrm{fmol} / 2 \mathrm{~min}$ fraction of one column, and remained nearly constant during the experimental period. We observed an almost constant amount of ACTH release during all subsequent pulses of OT. The increase in ACTH release due to OT returned to baseline values within $10 \mathrm{~min}$ after the stimulus was removed.

Using a similar protocol, the cells were exposed for 5 min to increasing concentrations of OT ( $0.1 \mathrm{nM}$ up to, 10 $\mu \mathrm{M})$. Each concentration was infused a total of three times in random order at $30 \mathrm{~min}$ intervals into one of three identical columns. OT-evoked release of ACTH was evident at $0.1 \mathrm{nM}$ and $\mathrm{ACTH}$ release increased dose dependently up to 20 -fold at $10 \mu \mathrm{M} \mathrm{OT}$, the highest concentration applied (Fig. 2).

\section{ACTH release by various secretagogues in physiological concentrations}

The release of ACTH elicited by physiological doses, based on hypophyseal portal blood concentrations, of OT (10 nM) (11), AVP (0.5 nM) (14), or CRF (0.1 nM) (13) is shown in Fig. 3. The results demonstrate that the potency of $10 \mathrm{nM}$ OT to induce ACTH secretion is lower compared to that of $0.5 \mathrm{nM}$ AVP or $0.1 \mathrm{nM}$ CRF. To our knowledge, in this and the previous experiments shown above, for the first time, a significant effect of OT in physiological concentration on ACTH release is demonstrated.

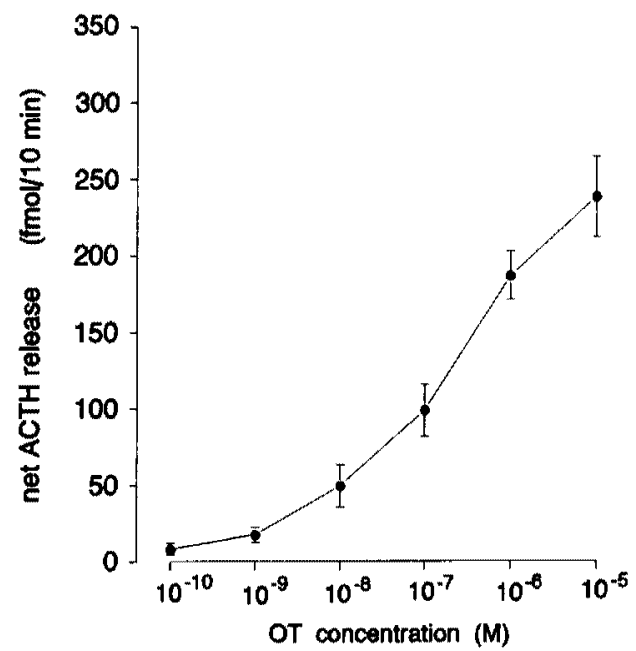

FIG. 2. Release of ACTH by perifused anterior pituitary cells in response to OT. Cells were exposed to different concentrations of OT for 5 min in a randomized, complete block design. Data are means of the net ACTH release; bars indicate the SEM $(n=3)$. The release caused by $0.1 \mathrm{nM}$ OT was significant at a level of $P<0.2 \mathrm{vs}$. basal release, and the release elicited by higher OT concentrations was significant at a level of $P<0.05$.

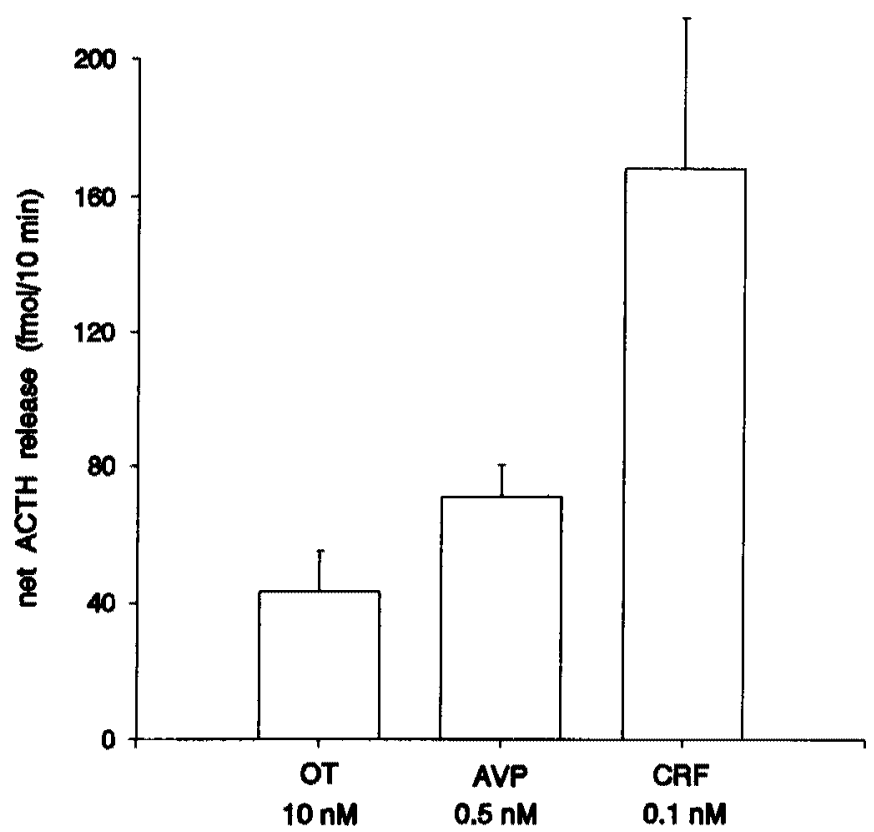

FiG. 3. ACTH release by perifused anterior pituitary cells after treatment with various secretagogues. ACTH secretion evoked by OT (10 nM), AVP (0.5 nM), or CRF ( $0.1 \mathrm{nM}$ ) is expressed as mean of the net ACTH released during three secretory responses. Each bar represents the mean \pm SEM. For all three substances evoked us. basal release was significant $(P<0.05)$.

\section{Release of ACTH by OT in the presence of CRF or AVP}

We also examined the ACTH release by OT in different concentrations in the presence of the two hypothalamic releasing hormones, CRF or AVP. Available evidence implies that both peptides are involved in the physiological regulation of ACTH secretion (2). To determine whether OT is a functional component of the releasing hormone cocktail regulating adenohypophyseal responses, the effects of these stimuli on ACTH release were examined. We tested the ACTH release response to CRF alone (0.1 nM) and to mixtures of CRF (0.1 nM) and OT in concentrations of $1 \mathrm{nM}, 10 \mathrm{nM}, 100 \mathrm{nM}, 1 \mu \mathrm{M}$, and $10 \mu \mathrm{M}$ (Fig. 4).

The data reveal that the ACTH-releasing effect of CRF was augmented in the presence of $O T$, because ACTH release by all five peptide combinations (open columns) was more than the calculated sum of ACTH release elicited by $\mathrm{CRF}$ and OT applied separately (hatched columns). The $10 \mathrm{~min}$ net ACTH release induced by the CRF/OT mixtures with OT concentrations of $100 \mathrm{nM}, 1 \mu \mathrm{M}$, and $10 \mu \mathrm{M}$ were $1.2,1.4$, and 1.7 times greater, respectively, than the sums of the responses to CRF and OT alone. The synergism of CRF and OT on ACTH release was significant over this range of concentrations.

In contrast, when AVP in a fixed concentration of 0.5 $\mathrm{nM}$ was perifused simultaneously with $\mathrm{OT}$ in different concentrations in the same experimental design as above, 


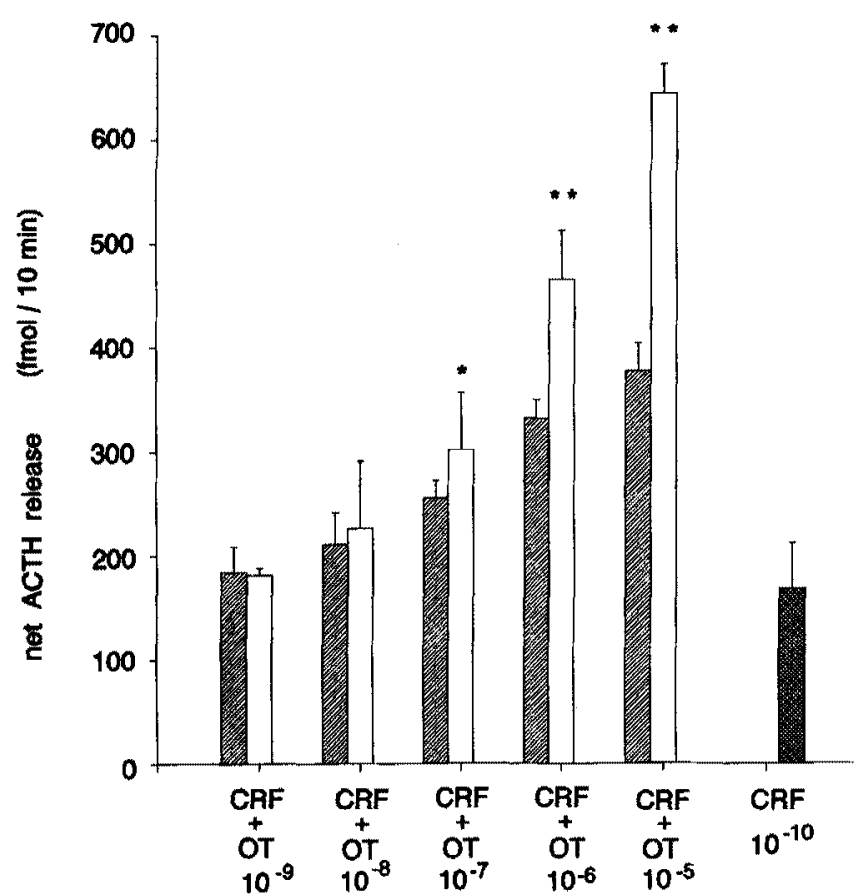

FIG. 4. ACTH release by perifused anterior pituitary cells evoked by OT in the presence of CRF. CRF (0.1 nM; cross-hatched column) or combinations of OT ( $1.0 \mathrm{nM}$ to $10 \mu \mathrm{M}$; see abscissa) and CRF (0.1 nM) were applied to perifusion columns. Open columns indicate ACTH release obtained with OT-CRF combinations; hatched columns represent ACTH released by $0.1 \mathrm{nM}$ CRF plus the ACTH released by OT in the concentrations indicated (see also Fig. 2). Data are means of the net release of hormone from three experiments \pm sEM. The synergistic effects of OT-CRF combinations was significant for CRF (0.1 nM) + OT [100 nM; $P<0.2\left(^{*}\right)$ ], and for CRF $(0.1 \mathrm{nM})$ with $1 \mu \mathrm{M}$ or $10 \mu \mathrm{M}$ OT $\left[P<0.05\left(^{* *}\right)\right]$. Note the scale of this figure is different from Fig. 2 and Fig. 5.

the ACTH release differed only slightly from the calculated sum of release when each peptide was added separately to the perifused cells (Fig. 5). The differences between calculated (hatched columns) and measured (open columns) ACTH release evoked by the AVP/OT combinations are not significant for any concentration of OT. These data indicate that the effect of OT on AVP. induced ACTH release when perifused simultaneously is additive. This additive effect implies similar or even identical mechanisms of intracellular signal transduction processes involved in the ACTH-releasing action of these two hormones.

\section{Changes in intracellular free calcium concentration caused by OT and AVP}

Cultures from 10 different cell preparations provided the individual adenohypophyseal cells analyzed for cytoplasmic free calcium. More than 500 cells were each stimulated with either AVP or OT in concentrations of $1 \mu \mathrm{M}$ and $100 \mathrm{nM}$, respectively. Calcium concentrations in each cell were recorded for periods of 90 or $120 \mathrm{sec}$. Basal resting intracellular calcium levels were stable and

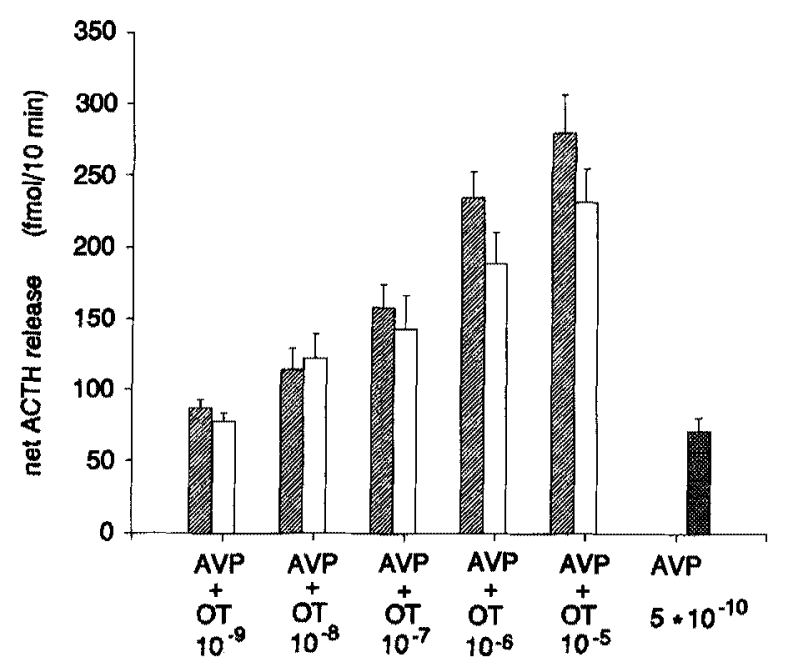

FrG. 5. Release of ACTH by perifused anterior pituitary cells evoked by OT in the presence of AVP. The ACTH release evoked by AVP ( 0.5 $\mathrm{nM}$; cross-hatched column) and by combinations of AVP ( $0.5 \mathrm{nM})$ with varying concentrations of OT (open columns) is shown. Data are means of three different experiments \pm SEM. The differences in net ACTH release evoked by the AVP-OT-combinations (open columns), compared to the calculated sum of the AVP-value plus respective OT. values (hatched columns), was not significant for any concentration of OT $(P>0.06)$.

ranged from 80-130 nM for responsive pituitary cells (n $=191$ individual cells out of 524 examined cells). Corticotrophs in the mixed population of anterior pituitary cells were later identified by immunocytochemistry.

Addition of OT (100 $\mathrm{nM}$ ) increased the cytosolic free calcium concentrations to values ranging from $500-800$ $\mathrm{nM}$ in 30 (of 32 ) identified corticotrophs. Increased intracellular calcium was evident within $3 \mathrm{sec}$, then declined in 10-15 sec toward a plateau slightly higher than the calcium concentration observed under resting conditions (Fig. 6A). It was possible to trigger a second and third (not shown) calcium transient from the same corticotroph cell provided that subsequent challenges were at least $10 \mathrm{~min}$ apart (Fig. 6B).

An equivalent increase in the calcium concentration was observed when corticotrophs, which were first stimulated with OT, were challenged subsequently with $1 \mu \mathrm{M}$ AVP ( 6 of 6 cells; Fig. 7). OT- or AVP-induced intracellular calcium concentration response profiles were not substantially different with respect to onset (rapid increase within $3 \mathrm{sec}$ ), height of peak, or rate of subsequent decrease to basal levels.

To explore whether the OT-induced increase in intracellular calcium was due to an influx of calcium or to a redistribution of intracellular stored calcium, we carried out a set of experiments in $0.1 \mu \mathrm{M}$ extracellular calcium, which corresponds to the basal value of intracellular calcium concentration as observed with Fura-2 measurements (see Figs. 6 and 7). The calcium concentration was buffered at $0.1 \mu \mathrm{M}$ free calcium with EGTA, and this low 
FIc. 6. Rise of OT-induced intracellular calcium in a single, immunocytochemically identified corticotroph. The corticotroph was subjected to two (A and B) consecutive stimuli of $100 \mathrm{nM}$ OT, separated by a $10 \mathrm{~min}$ intermission after washing. The intracellular free calcium level had returned to the prestimulation basal value before application of the second stimulus. Note the marked increase in free intracellular calcium immediately after OT application. Both calcium transients (A and $B$ ) were similar with a slightly higher basal level of calcium before the second stimulus.

FIG. 7. Increase in intracellular calcium of an identified corticotroph cell in response to both OT or AVP. A, Intracellular calcium rapidly increases in a single immunocytochemically identified corticotroph by a challenge with OT (100 nM). B, After a 10 min intermission and washing, the same cell was challenged with AVP $(1 \mu \mathrm{M})$. Arrows indicate additions of OT or AVP. The profiles shown are representative of six cells treated in the same manner.
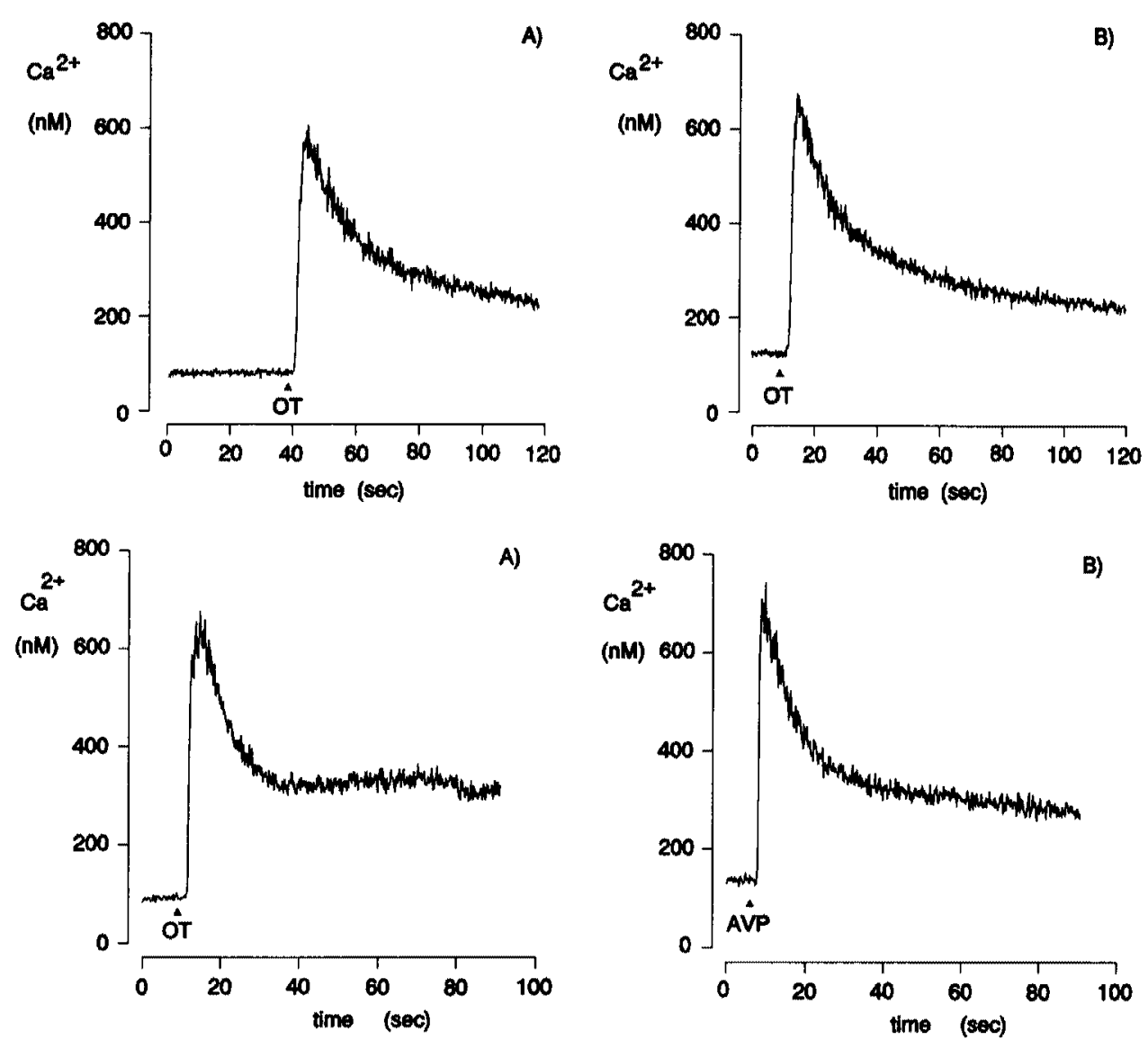

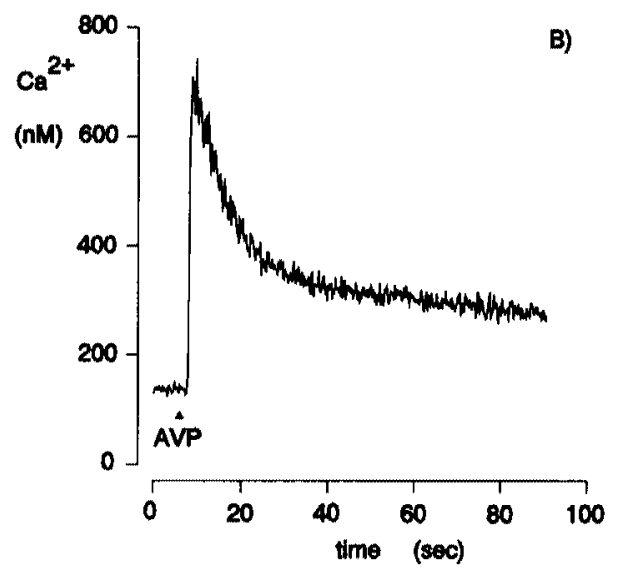

calcium concentration was controlled with a calciumselective electrode (34). After the $10 \mathrm{~min}$ intermission between different treatments, culture dishes were washed twice with the buffer containing $0.1 \mu \mathrm{M}$ free calcium, and cells were then submitted to subsequent treatments. First we determined the effect of depolarizing concentrations of $\mathrm{K}^{+}(48 \mathrm{mM})$. None of five analyzed cells, which exhibited a calcium transient in measuring buffer containing $1 \mathrm{mM}$ calcium, responded in $0.1 \mu \mathrm{M}$ extracellular calcium. However, four of these cells again showed a calcium transient when placed into measuring buffer containing $1 \mathrm{mM}$ calcium (see Materials and Methods), indicating the viability and the control of voltage-dependent calcium channels of the tested cells. Basal intracellular calcium levels in identified corticotrophs were similar at $0.1 \mu \mathrm{M}$ extracellular calcium compared to $1 \mathrm{mM}$ calcium. When OT (100 nM) was added to single cells in buffer containing $1 \mathrm{mM}$ calcium (see Figs. 6, 7A, and 8A), a remarkable increase in intracellular calcium concentration ranging from 500-800 $\mathrm{nM}$ was observed. At $0.1 \mu \mathrm{M}$ extracellular calcium, 8 of 12 corticotrophs also responded to OT. However, the rapidity of the increase in intracellular calcium was slower, and the decline period of calcium transients to basal values was longer (see Fig. $8 B$ ). Usually, we found peak values of intracellular free calcium ranging from 200-500 nM. These data support the notion that OT mobilizes a transient release of calcium mainly from an intracellular pool in single identified corticotroph cells.

\section{Discussion}

The data presented here show that $\mathrm{OT}$ at physiological concentrations stimulates ACTH secretion by isolated, rat adenohypophyseal corticotrophs and interacts in different ways with CRF or AVP in exerting their ACTH secretagoguic actions. OT markedly synergizes the ACTH secretagoguic activity of CRF and has an additive effect on AVP action. In addition, our results reveal a basic mechanism of OT action; specifically, it triggers an increase of intracellular calcium by mobilizing calcium from intracellular stores leading to ACTH secretion from pituitary corticotrophs.

Secretion of ACTH occurs in a pulsatile manner and is closely correlated with pulsatile releases of hypothalamic factors into hypophyseal portal blood $(35,36)$. We mimicked this process in a continuous, in vitro column perifusion system (30), whereby the isolated adenohypophyseal cells were stimulated for short periods of time ( $5 \mathrm{~min}$ ) at regular intervals with concentrations of secretagogues similar to those found in rat portal blood (11, 13-15). Interestingly, with 1-10 nM OT, i.e. in concen- 

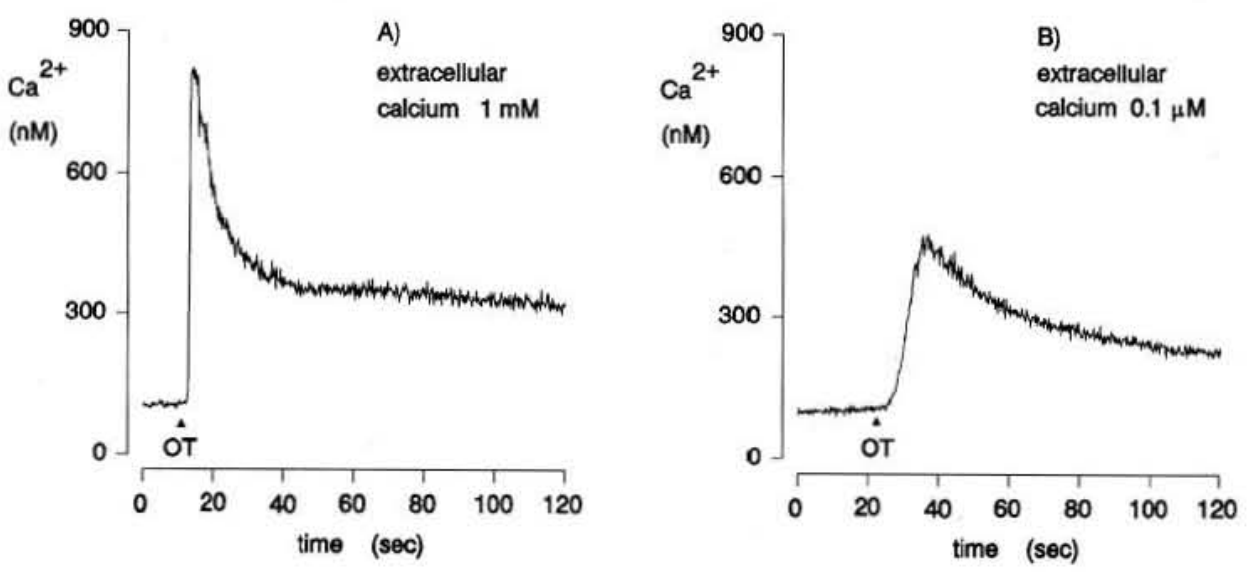

Fig. 8. Corticotroph responses to OT in $1 \mathrm{mM}$ and $0.1 \mu \mathrm{M}$ extracellular calcium. A, After the initial OT stimulus in the presence of $1 \mathrm{mM}$ calcium, the cells were washed with buffer containing $0.1 \mu \mathrm{M}$ free calcium. B, The response to $\mathrm{OT}$ at $0.1 \mu \mathrm{M}$ calcium implies that intracellular stores are involved. The calcium response is representative of 8 of 12 cells subjected to the same protocol. C, Video print of the adenohypophyseal cell, which responded to $\mathrm{OT}$ as shown in panels A and B. D, Identification of the cell as a corticotroph by ACTH-immunocytochemistry. Arrowhead points to the measured and identified corticotroph; arrows indicate neighboring ACTH negative cells; bar $=10 \mu \mathrm{M}$.
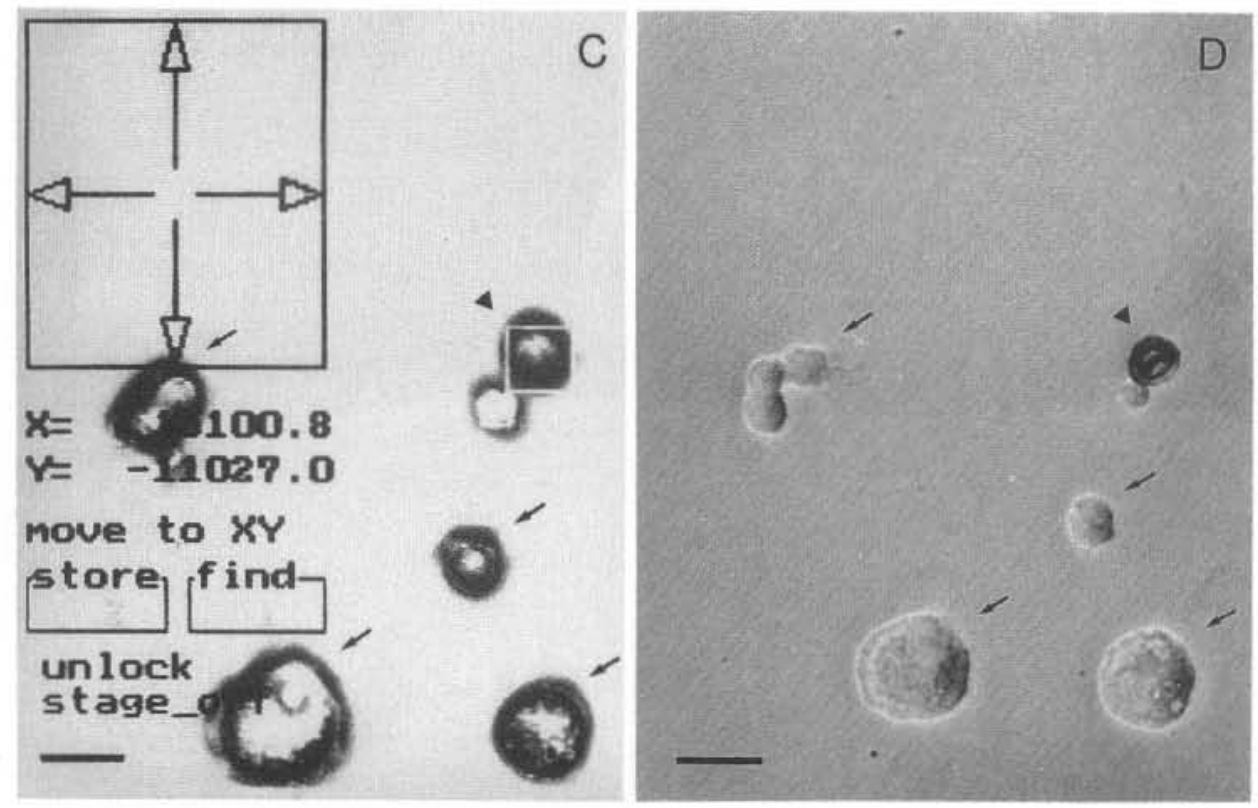

trations found in rat portal blood $(11,15)$, the release of ACTH was not saturated but increased in a dose-dependent manner up to $10 \mu \mathrm{M}$, the highest concentration tested. The threshold-stimulating concentration of OT was approximately $1 \mathrm{nM}$, which is close to estimates of the affinity [dissociation constant $\left(\mathrm{K}_{\mathrm{d}}\right)=1.5 \mathrm{nM}$ ] of specific receptors for OT measured in total adenohypophyseal membranes (7). Both the presence of separate receptors for AVP $(37,38)$ and OT $(7)$ and the ACTH secretion elicited by physiological OT concentrations suggest a specific role for OT in the regulation of ACTH secretion. In addition, various forms of stress are known to affect OT release in the rat (for review see Ref. 21). Several studies report 5- to 10 -fold increases of OT in blood plasma during stress $(4,39,40)$. A recent study (41) reported increased OT levels in cerebrospinal fluid, accompanied by increased plasma OT after different kinds of stress suggesting that cerebrospinal fluid hormone levels reflect to some degree the neurosecretory activity in the brain. Plotsky et al. (42) observed a 2-fold increase in portal blood OT concentration after hemorrhage as a stressor, but did not report OT values exceeding $3.5 \mathrm{nM}$ under their experimental conditions. To date, these data and our results suggest that ACTH secretion in the rat is physiologically regulated by $1-10 \mathrm{nM} O T$, although higher concentrations of OT can elicit a pronounced ACTH release. ACTH secretion by high concentrations of OT was also observed in earlier studies employing superfused hemipituitaries or cultured pituitary cells $(17,22,25)$.

The possibility of a role for OT release in the external zone of the median eminence $(8,9,43,44)$ into hypophyseal portal blood in the regulation of ACTH secretion is intriguing. Available evidence suggests that OT serves as an ACTH-releasing factor in the AVP-deficient Brattleboro rat (45). Moreover, previously reported data also reveal that $\mathrm{OT}$ in certain kinds of stress is involved in the regulation of ACTH secretion, supporting the con- 
cept of a multifactorial modulation by the hypothalamus $(21,42)$.

Our data obtained by pulsatile application of secretagogues show that OT given in combination with CRF or AVP significantly enhances ACTH secretion. In agreement with others $(16,21)$ we observed synergism between OT and CRF on ACTH release. In contrast to previous studies $(17,22)$ which did not reveal an OT effect on AVP-induced ACTH release, our data clearly demonstrate that simultaneous exposure to OT and AVP produces an additive effect on ACTH secretion. Thus, we conclude that the intracellular mechanism of action of AVP and OT appear to be similar, if not identical. This notion is supported by our observations of changes in cytosolic free calcium concentrations recorded with the calcium indicator Fura-2 in cultured, single, identified adenohypophyseal corticotrophs. These data further elucidate the mechanism of OT action on corticotroph ACTH release, because not only AVP but also OT evoked immediate increases in intracellular calcium levels in immunocytochemically identified corticotrophs. Since the corticotroph cells respond to OT even after removal of extracellular calcium, it seems reasonable to conclude that OT mobilizes calcium mainly from intracellular calcium stores. Previous studies using pituitary cell suspensions (46) or individual cells (24) also reported increased cytosolic free calcium and ACTH release in individual corticotrophs after challenges with AVP. Our data on the role of intracellular calcium stores are consistent with recent secretion studies carried out in calcium-free medium where ACTH release by OT was demonstrated, but it should be noted that depletion of intracellular calcium nearly abolished the OT response (25). The common mechanism which leads to the release of calcium from intracellular stores requires activation of phospholipase $\mathrm{C}$ and production of inositol 1,4,5-trisphosphate (for review see Ref. 47). Our findings are consistent with this mechanism and indicate that $\mathrm{OT}$ is an effective ACTH-secretagogue utilizing this pathway to trigger secretion in rat corticotrophs. The intracellular stores, from which inositol 1,4,5-tris-phosphate effectively releases calcium into the cytosol in endocrine cells, are large $(48,49)$, and it is likely that these stores in corticotrophs constitute a calcium reservoir available for AVP and OT secretagogic actions. Subsequently, calcium discharged into the cytosol directly triggers exocytosis as observed in $\alpha$-toxin permeabilized pituitary $(50,51)$ and other endocrine cells $(52,53)$.

Taken together, we conclude that physiological concentrations of OT evoke ACTH secretion from adenohypophyseal corticotrophs. Moreover, OT together with other ACTH secretagogues like AVP and CRF, can serve as important regulators of ACTH release during stress and under normal conditions. The mechanism of OT- induced ACTH release implies increases in intracellular calcium levels through calcium release from intracellular stores, which finally triggers exocytosis.

\section{Acknowledgments}

The authors wish to thank Ulrike Fröhlich for skillful technical assistance, G. B. Makara and K. Kovacs (Budapest, Hungary) for ACTH-antisera, and H. Traurig (Department of Anatomy and Neurobiology, University of Kentucky, Lexington, KY) for his constructive comments on this manuscript. We are grateful to Zeiss (Oberkochen, Germany) for providing the equipment for calcium measurements.

\section{References}

1. Vale W, Vaughan J, Smith M, Yamamoto G, Rivier J, Rivier C 1983 Effects of synthetic ovine corticotropin-releasing factor, glucocorticoids, catecholamines, neurohypophysial peptides, and other substances on cultured corticotrophic cells. Endocrinology 113:1121-1131

2. Antoni FA 1986 Hypothalamic control of adrenocorticotropin secretion: advances since the discovery of 41 -residue corticotropinreleasing factor. Endocr Rev 7:351-378

3. Rivier C, Plotsky PM 1986 Mediation by corticotropin releasing factor (CRF) of adenohypophysial hormone secretion. Annu Rev Physiol 48:475-494

4. Lang RE, Heil JWE, Ganten D, Hermann K, Unger T, Rascher W 1983 Oxytocin unlike vasopressin is a stress hormone in the rat. Neuroendocrinology 37:314-316

5. Gibbs DM 1986 Stress-specific modulation of ACTH secretion by oxytocin. Neuroendocrinology 42:456-458

6. Antoni FA 1984 Novel ligand specificity of pituitary vasopressin receptors in the rat. Neuroendocrinology 39:186-188

7. Antoni FA 1986 Oxytocin receptors in rat adenohypophysis: evidence from radioligand binding studies. Endocrinology 119:23932395

8. Dierickx K, Vandesande F, De Mey J 1976 Identification, in the external region of the rat median eminence, of separate neurophysin-vasopressin and neurophysin-oxytocin containing nerve fibres. Cell Tissue Res 168:141-151

9. Tannahill LA, Sheward WJ, Robinson ICAF, Fink G 1991 Corticotrophin-releasing factor- 41 , vasopressin and oxytocin release into hypophysial portal blood in the rat: effects of electrical stimulation of the hypothalamus, amygdala and hippocampus. J Endocrinol 129:99-107

10. Antoni FA, Fink G, Sheward WJ 1990 Corticotrophin-releasing peptides in rat hypophysial portal blood after paraventricular lesions: a marked reduction in the concentration of corticotrophinreleasing factor -41 , but no change in vasopressin. $J$ Endocrinol 125:175-183

11. Gibbs DM 1984 High concentrations of oxytocin in hypophysial portal plasma. Endocrinology 114:1216-1218

12. Horn AM, Robinson ICAF, Fink G 1985 Oxytocin and vasopressin in rat hypophysial portal blood: experimental studies in normal and Brattleboro rats. J Endocrinol 104:211-224

13. Gibbs DM, Vale W 1982 Presence of corticotropin releasing factorlike immunoreactivity in hypophysial portal blood. Endocrinology 111:1418-1420

14. Koenig JI, Meltzer HY, Devane GD, Gudelsky GA 1986 The concentration of arginine vasopressin in pituitary stalk plasma of the rat after adrenalectomy or morphine. Endocrinology 118:25342539

15. Fink G, Robinson ICAF, Tannahill LA 1988 Effects of adrenalectomy and glucocorticoids on the peptides CRF-41, AVP and oxytocin in rat hypophysial portal blood. J Physiol (Lond) 401:329345

16. Antoni FA, Holmes MC, Jones MT 1983 Oxytocin as well as vasopressin potentiate ovine CRF in vitro. Peptides 4:411-415

17. Gibbs DM, Vale W, Rivier J, Yen SSC 1984 Oxytocin potentiates 
the ACTH-releasing activity of CRF(41) but not vasopressin. Life Sci 34:2245-2249

18. Giguere V, Labrie F 1982 Vasopressin potentiates cyclic AMP accumulation and $\mathrm{ACTH}$ release induced by corticotropin-releasing factor (CRF). Endocrinology 111:1752-1754

19. Oki Y, Nicholson WE, Orth DN 1990 Role of protein kinase-C in the adrenocorticotropin secretory response to arginine vasopressin (AVP) and the synergistic response to AVP and corticotropinreleasing factor by perifused rat anterior pituitary cells. Endocrinology 127:350-357

20. Liu JH, Muse K, Contreras P, Gibbs D, Vale W, Rivier J, Yen SSC 1983 Augmentation of ACTH-releasing activity of synthetic corticotropin releasing factor (CRF) by vasopressin in women. J Clin Endocrinol Metab 57:1087-1089

21. Gibbs DM 1986 Vasopressin and oxytocin: hypothalamic modulators of the stress response: a review. Psychoneuroendocrinology 11:131-140

22. Watanabe T, Oki $Y$, Orth DN 1989 Kinetic actions and interactions of arginine vasopressin, angiotensin-II, and oxytocin on adrenocorticotropin secretion by rat anterior pituitary cells in the microperifusion system. Endocrinology 125:1921-1931

23. Watanabe T, Orth DN 1987 Detailed kinetic analysis of adrenocorticotropin secretion by dispersed rat anterior pituitary cells in a microperifusion system: effects of ovine corticotropin-releasing factor and arginine vasopressin. Endocrinology 121:1133-1145

24. Leong DA 1988 A complex mechanism of facilitation in pituitary ACTH cells: recent single-cell studies. J Exp Biol 139:151-168

25. Won JGS, Oki Y, Orth DN 1990 Roles of intracellular and extracellular calcium in the kinetic profile of adrenocorticotropin secretion by perifused rat anterior pituitary cells. II. Arginine vasopressin, oxytocin, and angiotensin-II stimulation. Endocrinology $126: 858-868$

26. Oki Y, Peatman TW, Qu Z-C, Orth DN 1991 Effects of intracellular calcium depletion and glucocorticoid on stimulated adrenocorticotropin release by rat anterior pituitary cells in a microperifusion system. Endocrinology 128:1589-1596

27. Portanova R, Smith DK, Sayers G 1970 A trypsin technic for the preparation of isolated rat anterior pituitary cells. Proc Soc Exp Biol Med 133:573-576

28. Dobson PRM, Brown BL 1985 The preparation of culture and incubation of rat anterior pituitary cells for static and dynamic studies of secretion. Methods Enzymol 109:293-298

29. Dayanithi G, Antoni FA 1989 Rapid as well as delayed inhibitory effects of glucocorticoid hormones on pituitary adrenocorticotropic hormone release are mediated by type II glucocorticoid receptors and require newly synthesized messenger ribonucleic acid as well as protein. Endocrinology 125:308-313

30. Gillies G, Lowry PJ 1978 Perfused rat isolated anterior pituitary cell column as bioassay for factor(s) controlling release of adrenocorticotropin: validation of a technique. Endocrinology 103:521527

31. Antoni FA, Dayanithi G 1990 Secretion of ACTH by perifused isolated rat anterior pituitary cells: pulses of secretagogue enhance the secretory response and modify the effect of atriopeptin. J Endocrinol 125:365-373

32. Grynkiewicz G, Poenie M, Tsien RY 1985 A new generation of calcium indicators with greatly improved fluorescence properties. J Biol Chem 260:3440-3450

33. Beyer C, Pilgrim C, Reisert I 1991 Dopamine content and metabolism in mesencephalic and diencephalic cell cultures: sex differences and effects of sex steroids. J Neurosci 11:1325-1333

34. Föhr KJ, Warchol W, Gratzl M, Calculation and control of free divalent cations in solutions used for membrane fusion studies. Methods Enzymol, in press

35. Tanaka K, Nicholson WE, Orth DN 1978 Diurnal rhythm and disappearance half-time of endogenous plasma immunoreactive $\beta$ MSH (LPH) and ACTH in man. J Clin Endocrinol Metab 46:883890

36. Engler D, Pham T, Fullerton MJ, Ooi G, Funder JW, Clarke IJ 1989 Studies of the secretion of corticotropin-releasing factor and arginine vasopressin into the hypophysial-portal circulation of the conscious sheep. Neuroendocrinology 49:367-381

37. Lutz-Bucher B, Koch B 1983 Characterization of specific receptors for vasopressin in the pituitary gland. Biochem Biophys Res Commun 115:492-498

38. Knepel W, Götz D, Fahrenholz F 1986 Interaction of rat adenohypophyseal vasopressin receptors with vasopressin analogues substituted at positions 7 and 1: dissimilarity from the V1 vasopressin receptor. Neuroendocrinology 44:390-396

39. Gibbs DM 1984 Dissociation of oxytocin, vasopressin and corticotropin secretion during different types of stress. Life Sci 35:487491

40. Dohanics J, Hoffman GE, Verbalis JG 1991 Hyponatremia-induced inhibition of magnocellular neurons causes stressor-selective impairment of stimulated adrenocorticotropin secretion in rats. Endocrinology 128:331-340

41. Ivanyi T, Wiegant VM, de Wied D 1991 Differential effects of emotional and physical stress on the central and peripheral secretion of neurohypophysial hormones in male rats. Life Sci 48:13091316

42. Plotsky PM, Bruhn TO, Vale W 1985 Evidence for multifactor regulation of the adrenocorticotropin secretory response to hemodynamic stimuli. Endocrinology 116:633-639

43. Vandesande F, Dierickx K 1975 Identification of the vasopressin producing and of the oxytocin producing neurons in the hypothalamic magnocellular neurosecretory system of the rat. Cell Tissue Res 164:153-162

44. Burlet A, Chateau M, Czernichow P 1979 Infundibular localization of vasopressin, oxytocin and neurophysins in the rat: its relationships with corticotrope function. Brain Res 168:275-286

45. Beny J-L, Baertschi AJ 1980 Oxytocin: major corticotropin-releasing factor secreted from diabetes insipidus rat posterior pituitary in vitro. Neuroendocrinology 31:261-264

46. Knepel W, Schöfl C 1987 Intracellular free calcium concentration in rat anterior pituitary cells as indicated by fura-2: effect of arginine-vasopressin. Naunyn-Schmiedebergs Arch Pharmacol 336:321-326

47. Berridge MJ, Irvine RF 1989 Inositol phosphates and cell signalling. Nature 341:197-205

48. Föhr KJ, Scott J, Ahnert-Hilger G, Gratzl M 1989 Characterization of the inositol 1,4,5-trisphosphate-induced calcium release from permeabilized endocrine cells and its inhibition by decavanadate and p-hydroxymercuribenzoate. Biochem J 262:83-89

49. Föhr KJ, Ahnert-Hilger G, Stecher B, Scott J, Gratzl M 1991 GTP and calcium modulate the inositol 1,4,5-trisphosphate dependent calcium release in streptolysin $O$-permeabilized bovine adrenal chromaffin cells. J Neurochem 56:665-670

50. Macrae MB, Davidson JS, Millar RP, van der Merwe PA 1990 Cyclic AMP stimulated luteinizing (lutropin) exocytosis in permeabilized sheep anterior-pituitary cells. Biochem J 271:635-639

51. van der Merwe PA, Millar RP, Wakefield IK, Davidson JS 1989 Mechanisms of luteinizing-hormone exocytosis in Staphylococcus aureus-alpha-toxin-permeabilized sheep gonadotropes. Biochem $\mathrm{J}$ 264:901-908

52. Ahnert-Hilger G, Bhakdi S, Gratzl M 1985 Minimal requirements for exocytosis. A study using PC 12 cells permeabilized with staphylococcal alpha-toxin. J Biol Chem 260:12730-12734

53. Bader M-F, Thiersẻ D, Aunis D, Ahnert-Hilger G, Gratzl M 1986 Characterization of hormone and protein release from alpha-toxinpermeabilized chromaffin cells in primary culture. $J$ Biol Chem 261:5777-5783 